\title{
Uso de subdoses de glyphosate na supressão de espécies forrageiras consorciadas com milho
}

\section{Use of glyphosate subdoses in the suppression of forage species intercropped with corn}

\author{
Matheus Lemos MATIAS ${ }^{1}$; Vinícius Oliveira GONÇALVES ${ }^{2}$; Guilherme Braga Pereira BRAZ ${ }^{3}$ \\ Christiano Lima Lobo ANDRADE ${ }^{4}$; Alessandro Guerra da SILVA ${ }^{5}$; Alberto Leão de Lemos BARROSO \\ ${ }^{1}$ Graduando em Agronomia da Universidade de Rio Verde, Fazenda Fontes do Saber. Rio Verde, Goiás, Brasil. E-mail: \\ lemosagro@hotmail.com. \\ ${ }^{2}$ Graduando em Agronomia da Universidade de Rio Verde, Fazenda Fontes do Saber. Rio Verde, Goiás, Brasil. E-mail: \\ $<$ viniciusoliveira082016@hotmail.com>. \\ ${ }^{3}$ Professor da Faculdade de Agronomia da Universidade de Rio Verde, Fazenda Fontes do Saber. CEP: 75.909-104. Rio \\ Verde, Goiás, Brasil. E-mail: guilhermebrag@gmail.com. *Autor para correspondência. \\ ${ }^{4}$ Doutorando em Ciências Agrárias, Instituto Federal Goiano, IF Goiano. Campus Rio Verde. Rod. Sul Goiana Km 01 - Zona \\ Rural. Rio Verde, Goiás, Brasil. E-mail: <christiano.instrutotia@gmail.com>. \\ ${ }^{5}$ Professor da Faculdade de Agronomia da Universidade de Rio Verde, Fazenda Fontes do Saber. Rio Verde, Goiás, Brasil. E- \\ mail: silvaag@yahoo.com.br. \\ ${ }^{6}$ Professor da Faculdade de Agronomia da Universidade de Rio Verde, Fazenda Fontes do Saber. Rio Verde, Goiás, Brasil. E- \\ mail: <allbarroso60@gmail.com>.
}

Recebido em: 30-04-2019; Aceito em: 23-07-2019

\begin{abstract}
Resumo
A principal estratégia para assegurar o desenvolvimento do milho livre da interferência da forrageira, quando este é cultivado em consórcio, consiste no uso de herbicidas para a supressão temporária da espécie consorciada. Apesar disto, ainda há limitações de informações para uso adequado desta prática de forma seletiva para a forrageira cultivada em consórcio. Mediante o exposto, objetivou-se avaliar a supressão de crescimento de capimruziziensis e BRS Tamani imposta por doses de glyphosate associadas ao estádio da forrageira no momento da aplicação, quando cultivadas em consórcio com milho tolerante ao herbicida. Um experimento foi realizado com capim-ruziziensis e outro com BRS Tamani. Os experimentos foram conduzidos em delineamento de blocos ao acaso, no arranjo fatorial $5 \times 2$, com quatro repetições, sendo adotadas cinco doses do glyphosate $(0 ; 58 ; 116 ; 174$ e $232 \mathrm{~g} \mathrm{ha}^{-1}$ ) associadas a dois estádios da espécie forrageira no momento da aplicação ( 2 a 4 perfilhos e 5 a 7 perfilhos). O capim-ruziziensis apresenta alta sensibilidade ao glyphosate em função do estádio de aplicação, enquanto para BRS Tamani este comportamento não foi visualizado. O glyphosate (58 $\mathrm{g} \mathrm{ha}^{-1}$ ) apresenta potencial para utilização na supressão de capim-ruziziensis quando aplicado em plantas com 5 a 7 perfilhos. Doses de glyphosate variando entre 58 e $116 \mathrm{~g} \mathrm{ha}^{-1}$, independentemente do estádio de aplicação, apresentam potencial para serem utilizadas na supressão de BRS Tamani.
\end{abstract}

Palavras-chave adicionais: Brachiaria ruziziensis; controle químico; integração lavoura-pecuária; Panicum maximum.

\begin{abstract}
The main strategy to ensure the development of corn free of forage interference when intercropped is the use of herbicides for the temporary suppression of the intercropped species. Despite this, there are still limitations of information for the appropriate use of this practice in a selective way for the forage cultivated in a consortium. The objective of this study was to evaluate the growth suppression of Congo grass and BRS Tamani imposed by glyphosate doses and stage of application when cultivated in a consortium with herbicide tolerant corn. An experiment was carried out with Congo grass and another with BRS Tamani. The experiments were conducted in a randomized completely block design in the $5 \times 2$ factorial arrangement, with four replications, evaluating five glyphosate doses $\left(0,58,116,174\right.$, and $\left.232 \mathrm{~g} \mathrm{ha}^{-1}\right)$ associated with two stages of the forage species at the application time (2 a 4 tillers and 5 to 7 tillers). The Congo grass presents high sensitivity to glyphosate as a function of the application stage, whereas for BRS Tamani this behavior was not observed. Glyphosate (58 $\left.\mathrm{g} \mathrm{ha}^{-1}\right)$ has potential for use in the suppression of Congo ruziziensis when applied to plants with 5 to 7 tillers. Doses of glyphosate varying between 58 and $116 \mathrm{~g} \mathrm{ha}^{-1}$, regardless of the application stage, have potential to be used in the suppression of BRS Tamani.
\end{abstract}

Additional keywords: Brachiaria ruziziensis; chemical control; livestock agriculture integration; Panicum maximum. 


\section{Introdução}

Nos últimos anos, o aumento na demanda por alimentos promoveu a busca por novas estratégias de manejo, visando à otimização do uso da terra e ao aumento de produtividade. Dentre estas práticas, a integração lavoura-pecuária destaca-se como uma das mais promissoras em função da diversificação da produção, aumento da rentabilidade e principalmente pelos benefícios agronômicos gerados em comparação com áreas conduzidas sob a sucessão soja-milho (Balbinot Júnior, 2009; Pariz et al., 2009 e 2011).

De modo geral, mesmo em áreas conduzidas sob sistema de plantio direto, é comum encontrar taIhões com baixa cobertura de solo pela palhada (Ceccon, 2013) em função da rápida decomposição dos restos culturais, fato que contribuiu para o aumento de problemas com a compactação dos solos, diminuindo a disponibilidade hídrica para as plantas cultivadas (Seidel et al., 2014). Dessa forma, a consorciação de culturas proporciona o aumento no acúmulo de matéria seca e, consequentemente, melhorias nas características físicas, químicas e biológicas dos solos. Adicionalmente, a adoção destes sistemas de cultivo permite a quebra de ciclo de doenças e pragas e beneficia o controle de plantas daninhas e, consequentemente, possibilita a elevação do potencial produtivo (Jakelaitis et al., 2005 e 2006).

Neste contexto, o milho corresponde ao principal cereal empregado nos sistemas de consórcio, em função de sua alta adaptabilidade edafoclimática, e por apresentar bom retorno econômico quando explorado em ambiente de segunda safra (Silva et al., 2014). Entre os métodos mais empregados para a implantação do consórcio, destaca-se a semeadura simultânea do milho com a forrageira, podendo ser na mesma linha ou na entrelinha da cultura de interesse econômico; entretanto, estes podem tornar-se prejudiciais ao milho em função da competição interespecífica imposta pela forrageira no desenvolvimento inicial da cultura (Chioderoli et al., 2012; Ikeda et al., 2013). Dessa forma, as características das forrageiras devem ser levadas em consideração para o estabelecimento dos métodos de implantação e estratégias de manejo, para que não sejam observadas perdas de produtividade no milho e/ou falhas na implantação da espécie consorciada (Jakelaitis et al., 2010; Rodrigues et al., 2018).

Entre as forrageiras comumente utilizadas em sistemas consorciados com o milho, cita-se o capimruziziensis e espécies do gênero Panicum $\mathrm{sp}$. $\mathrm{O}$ capim-ruzizensis possui rápido desenvolvimento inicial, adaptabilidade ao sombreamento e facilidade de ser controlado com o herbicida glyphosate, visando à dessecação pré-semeadura da soja (Dan, 2013). O Panicum maximum possui porte baixo, porém alta capacidade de perfilhamento e produção de folhas. Um fato comum a ambas as forrageiras está relacionado ao sistema radicular profundo e à elevada tolerância à deficiência hídrica, características essenciais para a adaptação da forragem ao sistema de consórcio (Concenco et al., 2014; Lima et al., 2018).
Para assegurar o desenvolvimento inicial do milho livre da interferência imposta pela espécie em consórcio, a principal estratégia utilizada na supressão temporária das forrageiras consiste na aplicação de herbicidas em pós-emergência. Entretanto, um fator limitante a esta técnica é a disponibilidade de herbicidas registrados para a cultura do milho que apresentem seletividade para a espécie consorciada (Dan et al., 2011). Trabalhos disponíveis na literatura, em consórcios implantados com híbridos de milho convencional, vêm demonstrando potencial de utilização dos herbicidas atrazine, mesotrione e nicosulfuron (Ceccon et al., 2010; Petter et al., 2011).

No âmbito de buscar alternativas para supressão de espécies consorciadas com milho, em lavouras semeadas com híbridos $\mathrm{RR}^{\circledR}$, uma possibilidade refere-se à utilização de baixas doses de glyphosate, uma vez que o custo deste ingrediente ativo é menor em relação aos outros herbicidas registrados para a cultura. Em trabalho realizado com diferentes espécies do gênero Brachiaria sp., foi comprovado que estas possuem tolerância diferencial ao herbicida glyphosate (Brighenti et al., 2011). Por outro lado, Silva et al. (2016), avaliando o uso de glyphosate na supressão de crescimento de espécies em consórcio com o miIho, atestaram que doses variando entre 96 e $144 \mathrm{~g}$ ha $^{-1}$ têm potencial para supressão de $B$. brizantha, em aplicações realizadas sob plantas com 4 perfilhos.

Diante disto, o objetivo deste trabalho foi avaliar os efeitos de subdoses de glyphosate associadas ao estádio da forrageira, no momento da aplicação, em suprimir o desenvolvimento da capim-ruziziensis (Brachiaria ruziziensis) e BRS Tamani (Panicum maximum), em consórcio com o milho tolerante ao herbicida.

\section{Material e métodos}

Os experimentos foram implantados lado a lado e conduzidos a campo na segunda safra de 2018 no município de Rio Verde, Goiás (17\%27'05,54" S; 5057'53,47" O; 779 m altitude). O período de condução dos experimentos foi de 16-03-18 a 10-06-2018.

O clima na localidade, segundo a classificação de Köppen, é do tipo Aw, sendo caracterizado como clima tropical com estação seca, apresentando chuvas mais intensas no verão em relação ao inverno. Os dados de precipitação e temperatura média do ar durante a condução do experimento estão apresentados na Figura 1.

A área escolhida encontrava-se em sistema de plantio direto, tendo como cultura antecessora a soja. O solo da área experimental foi classificado como Latossolo Vermelho distrófico (Santos et al., 2013). As amostras de solo foram coletadas na profundidade de 0-20 cm, revelando as seguintes características físicoquímicas: $\mathrm{pH}$ em $\mathrm{CaCl}_{2}$ de 5,2; $\mathrm{Ca}^{+2}$ 2,0; $\mathrm{de}^{\mathrm{Mg}}{ }^{+2}$ 1,09;

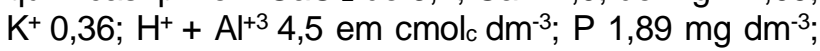
M.O 23,70 g kg-1; $580 \mathrm{~g} \mathrm{~kg}^{-1}$ de argila, $80 \mathrm{~g} \mathrm{~kg}^{-1}$ de silte, $340 \mathrm{~g} \mathrm{~kg}^{-1}$ de areia, pertencente à classe textura argilosa. 


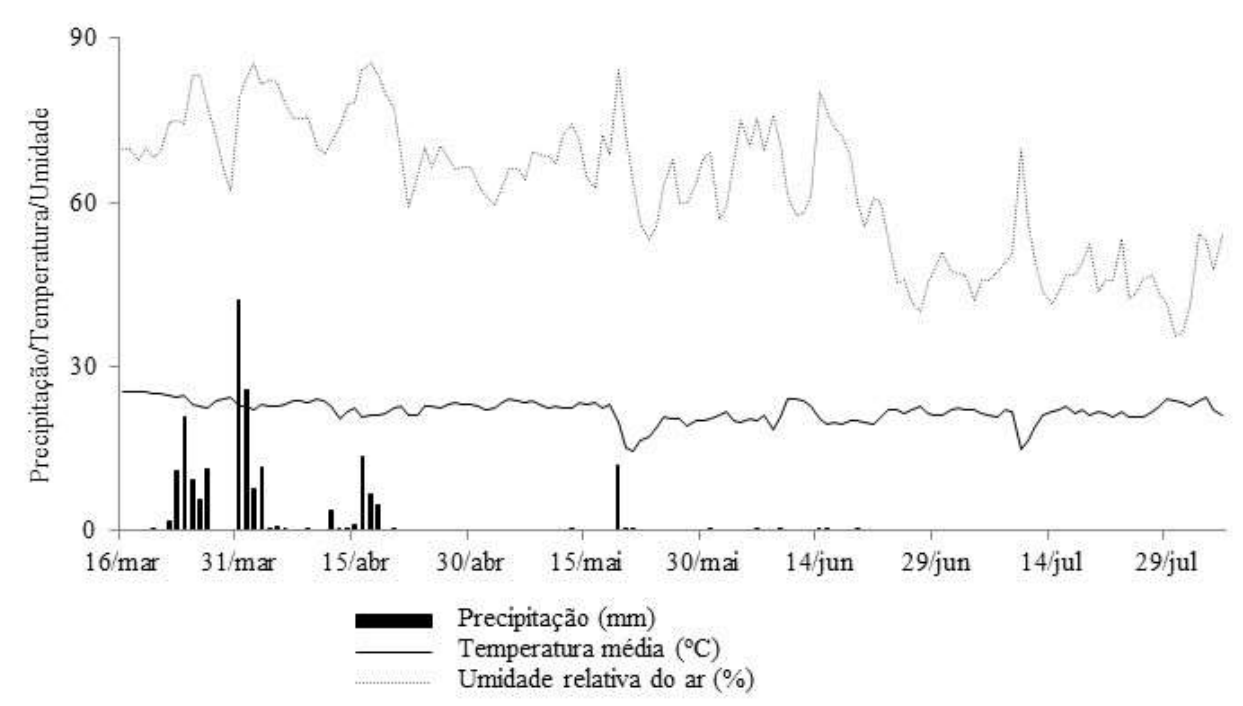

Figura 1 - Dados climatológicos durante o período de condução dos experimentos com uso de subdoses de glyphosate para supressão de gramíneas forrageiras em consórcio com milho. Rio Verde (GO), 2018. Climatic data during the period of experiments conduction using glyphosate subdoses for suppression of forage grasses in consortium with corn. Rio Verde (GO), 2018.

O delineamento utilizado foi o de blocos ao acaso, com quatro repetições. Foi adotado o arranjo fatorial $5 \times 2$, sendo que os níveis do primeiro fator foram compostos pelas subdoses de glyphosate $(0 ; 58$; 116; 174 e $232 \mathrm{~g} \mathrm{ha}^{-1}$ ) associadas aos estádios da espécie forrageira no momento da aplicação (2 a 4 e 5 a 7 perfilhos). $O$ híbrido de milho utilizado no experimento foi o NS $90^{\circledR}$ (Nidera Sementes ${ }^{\circledR}$ ) de ciclo: médio, grão semiduro e alaranjado. Já as forrageiras para cobertura de solo foram: capim-ruzizensis ( $B$. ruzizensis), que apresenta crescimento cespitoso, altura média de 0,5 a 0,7 m utilizado em pastoreio direto e formação de palhada, com produção anual de massa seca variando de $10 \mathrm{a} 18 \mathrm{t} \mathrm{ha}^{-1}$ e boa tolerância à seca; e o BRS Tamani ( $P$. maximum), que possui crescimento cespitoso, altura média de 0,8 a $1,3 \mathrm{~m}$, utilizado em pastoreio direto, com produção de massa seca variando de 25 a $28 \mathrm{t} \mathrm{ha}^{-1}$ e boa tolerância à seca.

Para as aplicações de glyphosate, foi utilizado o produto comercial Roundup Original ${ }^{\circledR}$ (sal de isopropilamina; Concentração $480 \mathrm{~g} \mathrm{~L}^{-1}$; suspensão concentrada). As unidades experimentais foram compostas por cinco linhas (milho) de 5,0 m, espaçadas a 0,5 m, e 4 linhas da espécie consorciada, de acordo com a forrageira prevista em cada experimento. Para as avaliações, foram consideradas as 3 linhas centrais do milho, desconsiderando $0,5 \mathrm{~m}$ das extremidades, apresentando, portanto, $6 \mathrm{~m}^{2}$. A semeadura foi realizada em 16 de março de 2018, de forma mecanizada, com densidade de semeadura de 3,5 sementes por metro. As espécies forrageiras foram semeadas manualmente nas entrelinhas do milho, com distribuição de $5 \mathrm{~kg} \mathrm{ha}^{-1}$ de sementes. Não foi utilizado adubação no sulco de semeadura, sendo aproveitada a adubação residual utilizada na soja. As adubações de cobertura foram realizadas quando as plantas de milho estavam com cinco e oito folhas completamente expandidas $\left(V_{5}\right.$ e $\left.V_{8}\right)$, sendo empregada a dose de $145 \mathrm{~kg} \mathrm{ha}^{-1}$ de ureia, em cada aplicação.

As aplicações dos tratamentos foram realizadas com pulverizador costal com pressurização por $\mathrm{CO}_{2}$ regulada a $2,5 \mathrm{kgf} \mathrm{cm}^{-2}$, munido de barra com seis pontas tipo TT 110-02, com leque duplo e volume de calda equivalente a $150 \mathrm{~L} \mathrm{ha}^{-1}$. É importante destacar que todas as aplicações foram realizadas preconizando-se as recomendações de clima para esta operação, estando sempre com umidade relativa do ar superior a $50 \%$, temperaturas não ultrapassando $30 \stackrel{\circ}{\circ}$ e intensidade de velocidade do vento baixa. Todos os tratamentos foram manejados com capina manual para evitar a interferência das plantas daninhas no desenvolvimento das forrageiras.

Para avaliar o efeito dos tratamentos, foi avaliada a fitointoxicação percentual causada na espécie forrageira, realizada aos 7; 14 e 28 dias após a aplicação do herbicida (DAA) (escala visual em que 0 representa ausência de sintomas e $100 \%$ representa morte das plantas (SBCPD, 1995)) e massa seca de parte aérea da forrageira aos 30 DAA (a parte aérea foi acondicionada em sacos de papel e colocada para secar em estufa de circulação forçada de ar, pelo período de 72 horas, em temperatura de $65{ }^{\circ} \mathrm{C}$, e posteriormente pesadas, sendo os resultados expressos em gramas).

Todos os dados foram submetidos à análise de variância, com o emprego do teste $\mathrm{F}$. Uma vez constatado efeito significativo, foi empregado o teste $\mathrm{F}$ $(p<0,05)$ para a comparação dos estádios de aplicação, e a análise de regressão para o ajuste do comportamento das doses de glyphosate. 


\section{Resultados e discussão}

\section{Experimento 1: Capim-ruziziensis}

Para todas as variáveis-respostas, foi observado efeito da interação entre doses de glyphosate $e$ estádio, demonstrando que o efeito do herbicida é variado de acordo com o momento em que a aplicação é realizada sob as plantas de capim-ruziziensis (Tabela 1). Na primeira avaliação de intoxicação de capim-ruziziensis (7 DAA), nota-se efeito linear positivo com relação às doses de glyphosate e aumento dos níveis de injúrias às plantas, independentemente do estádio de aplicação (Figura 2A). Apesar disto, quando se observa o coeficiente angular das equações, fica evidente a maior sensibilidade das plantas que receberam aplicação em estádios mais precoces do que quando comparadas àquelas em que a utilização do glyphosate, visando à supressão, foi realizada mais tardiamente.

Tabela 1 - Resumo da análise de variância de fitointoxicação (Fito) aos 7; 14 e 28 dias após a aplicação (DAA) e massa seca da parte aérea, no experimento com uso de subdoses de glyphosate, para supressão de capimruziziensis cultivado em consórcio com milho. Rio Verde (GO), 2018. Summary of variance analysis of phytotoxicity (Fito) at 7, 14 and 28 days after application (DAA) and shoot dry mass in the experiment using glyphosate subdoses for suppression of Congo grass in consortium with corn. Rio Verde (GO), 2018.

\begin{tabular}{lcccc}
\hline \multicolumn{5}{c}{ Resumo da análise de variância $\left(F_{\text {Calculado }}\right)$} \\
\hline Fonte de variação & Fito - 7 DAA & Fito - 14 DAA & Fito - 28 DAA & Massa seca \\
\hline Dose & $151,23^{*}$ & $130,54^{*}$ & $273,48^{*}$ & $56,01^{*}$ \\
Estádio & $144,99^{*}$ & $65,67^{*}$ & $77,96^{*}$ & $36,93^{*}$ \\
D x E & $13,04^{*}$ & $5,64^{*}$ & $9,30^{*}$ & $3,94^{*}$ \\
\hline CV $(\%)$ & 17,03 & 17,80 & 10,75 & 34,38 \\
\hline
\end{tabular}

**; * e ns: significativo a $1 \%$ e a $5 \%$, e não significativo a $5 \%$ de probabilidade, pelo teste $\mathrm{F}$, respectivamente.

Com relação à intensidade de injúrias observadas pela aplicação de glyphosate sob as plantas de capim-ruziziensis, observa-se que os resultados se assemelham aos apresentados por Costa et al. (2013), em que doses do herbicida variando entre $90 \mathrm{e}$ $180 \mathrm{~g} \mathrm{ha}^{-1}$ do glyphosate proporcionaram $50 \%$ de intoxicação. Esta rápida ação do glyphosate em promover elevados níveis de intoxicação às plantas de capim-ruziziensis, está relacionada à rápida absorção e translocação do herbicida até o sitio de ação (Brighenti et al., 2011). Nestas situações de estresses abióticos, as plantas tentam desencadear mecanismos de detoxificação da molécula, para tentar sobreviver à ação que o herbicida provoca (Merotto et al., 2015). Para que as plantas consigam minimizar os efeitos tóxicos proporcionados pelo herbicida, é necessário que estas se encontrem sob condições edafoclimáticas adequadas (Costa et al., 2013). Em situações em que há ação conjunta dos herbicidas e estresses provocados pela falta de água e altas temperaturas e radicação solar, as plantas podem entrar em colapso, ocorrendo sua morte.

Novamente, aos 14 DAA, verificou-se que o aumento de doses de glyphosate proporcionou acréscimo nos níveis de intoxicação de capim-ruziziensis, observando maior sensibilidade das plantas que receberam aplicação do herbicida em estádios mais jovens de desenvolvimento (Figura 2B). Pontualmente, apenas as doses inferiores a $58 \mathrm{~g} \mathrm{ha}^{-1}$ de glyphosate foram capazes de promover intoxicação menor que $40 \%$. A alta suscetibilidade de espécies do gênero Brachiaria sp. já foi indicada na literatura, especialmente para capim-ruziziensis (Brighenti et al., 2011). Um fato interessante é que esta alta sensibilidade do capim-ruziziensis ao glyphosate fez com que sua aceitação pelos produtores em sistemas consorciados fosse elevada, pois na ocasião da semeadura da soja em sucessão, a dessecação da espécie é facilitada pelo uso de baixas doses do herbicida.

Aos 28 DAA, fica ainda mais evidente a elevada sensibilidade do capim-ruziziensis ao glyphosate, indicando potencial de uso deste herbicida em função de doses e estádio de aplicação, tanto para a supressão do crescimento desta espécie, como para promover seu controle (Figura 2C). Nesta avaliação, fica claro que nenhuma das doses de glyphosate empregada apresenta potencial para ser utilizada na supressão de capim-ruziziensis, quando as aplicações foram realizadas em plantas no primeiro estádio (2 a 4 perfiIhos). Por outro lado, para aplicações realizadas em plantas com 5 a 7 perfilhos (Estádio II), verificou-se potencial de uso, visando à supressão de crescimento, de doses de glyphosate próximas a $58 \mathrm{~g} \mathrm{ha}^{-1}$, visto que estas proporcionaram níveis de intoxicação inferiores a $40 \%$. Esta supressão às plantas de capim-ruziziensis pelo uso do herbicida, aliado ao sombreamento proporcionado pelo milho, pode ser capaz de atenuar os efeitos da matocompetição da forrageira com a cultura, explorando ao máximo o benefício da semeadura consorciada (Ceccon et al., 2010).

Para massa seca de parte aérea do capim-ruziziensis, o comportamento observado assemelhou-se ao registrado para as avaliações de fitointoxicação, dado que, à medida que se procedeu ao aumento de doses de glyphosate, houve redução no acúmulo de massa seca (Figura 2D). Com relação ao efeito do estádio, verificou-se, novamente, maior sensibilidade do capim-ruziziensis ao herbicida quando as aplicações foram realizadas em plantas com 2 a 4 perfilhos, em comparação com a aplicação realizada no estádio de 5 a 7 perfilhos. De maneira geral, plantas mais 
jovens possuem sistema radicular pouco desenvolvido e menor cerosidade no limbo foliar; além disso, apresentam baixa capacidade de se detoxificar do glypho-
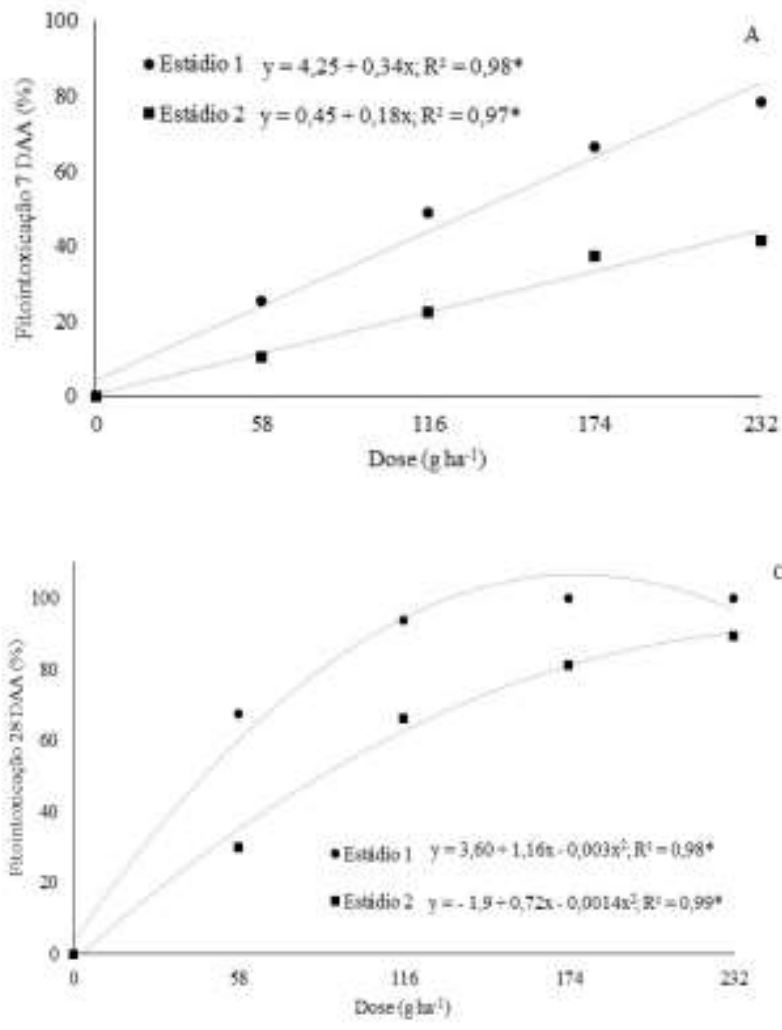

sate, aumentando sua sensibilidade ao herbicida (Monquero et al., 2005).
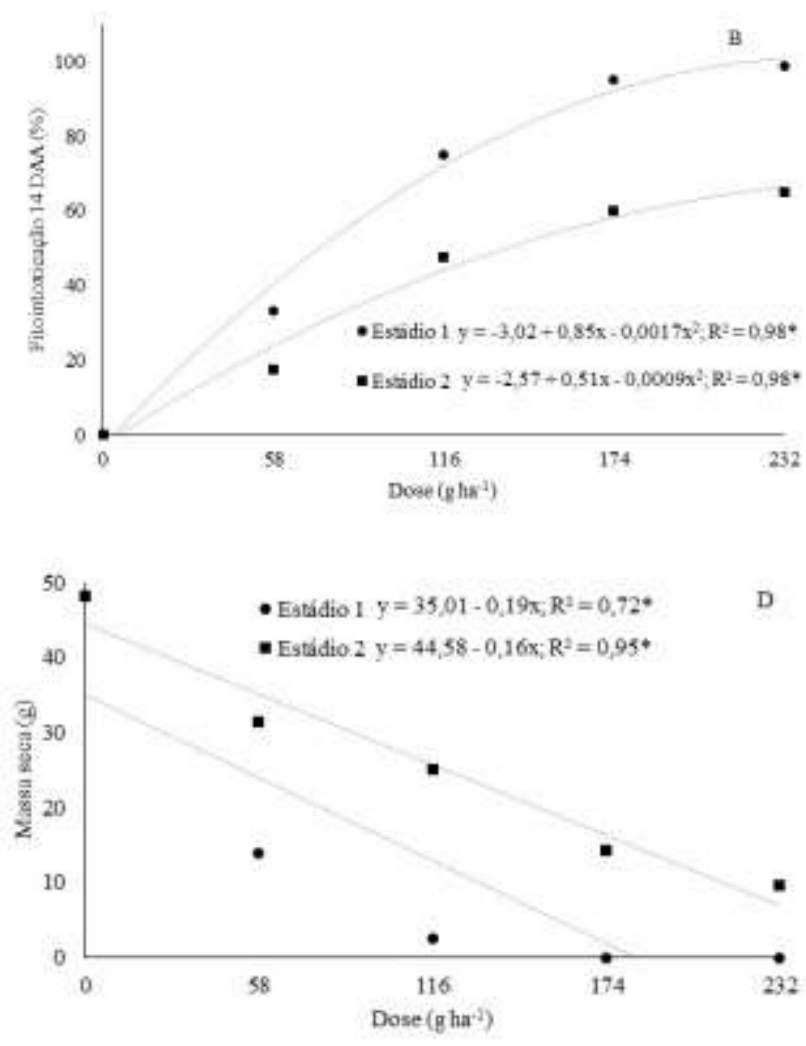

Figura 2 - Fitointoxicação aos 7; 14 e 28 dias após a aplicação (DAA) de glyphosate e massa seca de parte aérea de capim-ruziziensis. Rio Verde (GO), 2018. Phytointoxification at 7, 14 and 28 days after application (DAA) of glyphosate and shoot dry mass of Congo grass. Rio Verde (GO), 2018.

De modo geral, visando à utilização do glyphosate na supressão de capim-ruziziensis, verifica-se que há necessidade de as aplicações deste herbicida serem realizadas de forma mais tardia. Além disso, doses de glyphosate superiores a $58 \mathrm{~g} \mathrm{ha}^{-1}$ proporcionam elevados níveis de intoxicação, bem como acentuada redução na massa seca de parte aérea, mesmo quando aplicadas em plantas de capim-ruziziensis com 5 a 7 perfilhos. Neste sentido, verifica-se potencial de utilização do glyphosate para supressão desta espécie, desde que as aplicações sejam realizadas sob plantas em estádios de desenvolvimento mais avançados, bem como em doses próximas de $58 \mathrm{~g} \mathrm{ha}^{-1}$.

\section{Experimento 2: BRS Tamani}

A fitointoxicação aos 7 DAA foi influenciada tanto pelas doses de glyphosate como devido ao estádio de aplicação, enquanto para esta variável aos 28 DAA e para massa seca de parte aérea de BRS Tamani, só foi visualizado efeito das doses do herbicida (Tabela 2). Por outro lado, apenas para fitointoxicação aos 14 DAA, foi visualizado efeito da interação entre doses de glyphosate e estádio de aplicação do herbicida. Aos 7 DAA, plantas de BRS Tamani que receberam aplicação em estádio de desenvolvimento mais avançado (5 a 7 perfilhos) apresentavam maiores níveis de injúrias. Isto pode estar relacionado ao maior índice de área foliar que estas plantas possuíam na ocasião da aplicação, fato que possibilitou a maior absorção do herbicida (SPADER e VIDAL, 2001).

Aos 7 DAA, observa-se comportamento linear positivo para a variável fitointoxicação, uma vez que, à medida que houve aumento de dose de glyphosate, maiores intensidades de injúrias foram visualizadas nas plantas de BRS Tamani (Figura 3A). Este comportamento corrobora o verificado por Concenco et al. (2014), onde os autores verificaram que o aumento de doses de glyphosate ocasionou amarelecimento geral de plantas de Panicum maximum cv aruana cultivada em consórcio com a soja.

$\mathrm{Na}$ avaliação de fitointoxicação realizada aos 14 DAA, novamente se observa tendência de aumento das injúrias às plantas de BRS Tamani com o incremento de dose aplicada de glyphosate (Figura 3B). Nesta ocasião, verificou-se que plantas que receberam aplicação do herbicida em estádio mais precoce, apresentaram maior sensibilidade ao glyphosate, visto que o coeficiente angular da equação foi mais elevado. Apesar disto, com base nos níveis de intoxicação 
visualizados aos 14 DAA, verifica-se potencial de utilização de doses variando entre 58 e $116 \mathrm{~g} \mathrm{ha}^{-1}$, para supressão de crescimento da forrageira em consórcio com milho, dado que os valores não ultrapassaram o patamar de $40 \%$. Comparando os níveis de fitointoxi- cação obtidos nos dois experimentos do presente trabalho, fica evidente que a espécie BRS Tamani apresenta uma tolerância maior ao herbicida glyphosate em relação ao capim-ruziziensis.

Tabela 2 - Resumo da análise de variância de fitointoxicação (Fito) aos 7; 14 e 28 dias após a aplicação (DAA) e massa seca da parte aérea no experimento com uso de subdoses de glyphosate para supressão de BRS Tamani cultivado em consórcio com milho. Rio Verde (GO), 2018. Summary of variance analysis of phytotoxicity (Fito) at 7, 14 and 28 days after application (DAA) and shoot dry mass in the experiment using glyphosate subdoses for suppression of BRS Tamani in consortium with corn. Rio Verde (GO), 2018.

\begin{tabular}{lcccc}
\hline \multicolumn{5}{c}{ Resumo da análise de variância (FCalculado) } \\
\hline FV & Fito - 7 DAA & Fito - 14 DAA & Fito - 28 DAA & Massa seca \\
\hline Dose & $17,20^{*}$ & $39,16^{*}$ & $39,91^{*}$ & $9,39^{*}$ \\
Estádio & $5,90^{*}$ & $5,27^{\text {NS }}$ & $3,19^{\mathrm{NS}}$ & $1,62^{\mathrm{NS}}$ \\
D x E & $0,91^{\mathrm{NS}}$ & $3,42^{*}$ & $1,26^{\mathrm{NS}}$ & $0,35^{\mathrm{NS}}$ \\
\hline CV (\%) & 53,54 & 31,81 & 31,47 & 69,35 \\
\hline \multirow{2}{*}{ Estádio } & $7 \mathrm{DAA}$ & Fitointoxicação $(\%)$ & \multirow{2}{*}{ Massa seca (g) } \\
\hline Estádio I & $22,50 \mathrm{~b}$ & $14 \mathrm{DAA}$ & 28 DAA & 6,43 a \\
Estádio II & $34,15 \mathrm{a}$ & $35,00 \mathrm{a}$ & $52,00 \mathrm{a}$ & $8,52 \mathrm{a}$ \\
\hline
\end{tabular}

**; * e ns: significativo a $1 \%$ e a $5 \%$, e não significativo a $5 \%$ de probabilidade, pelo teste $\mathrm{F}$, respectivamente.
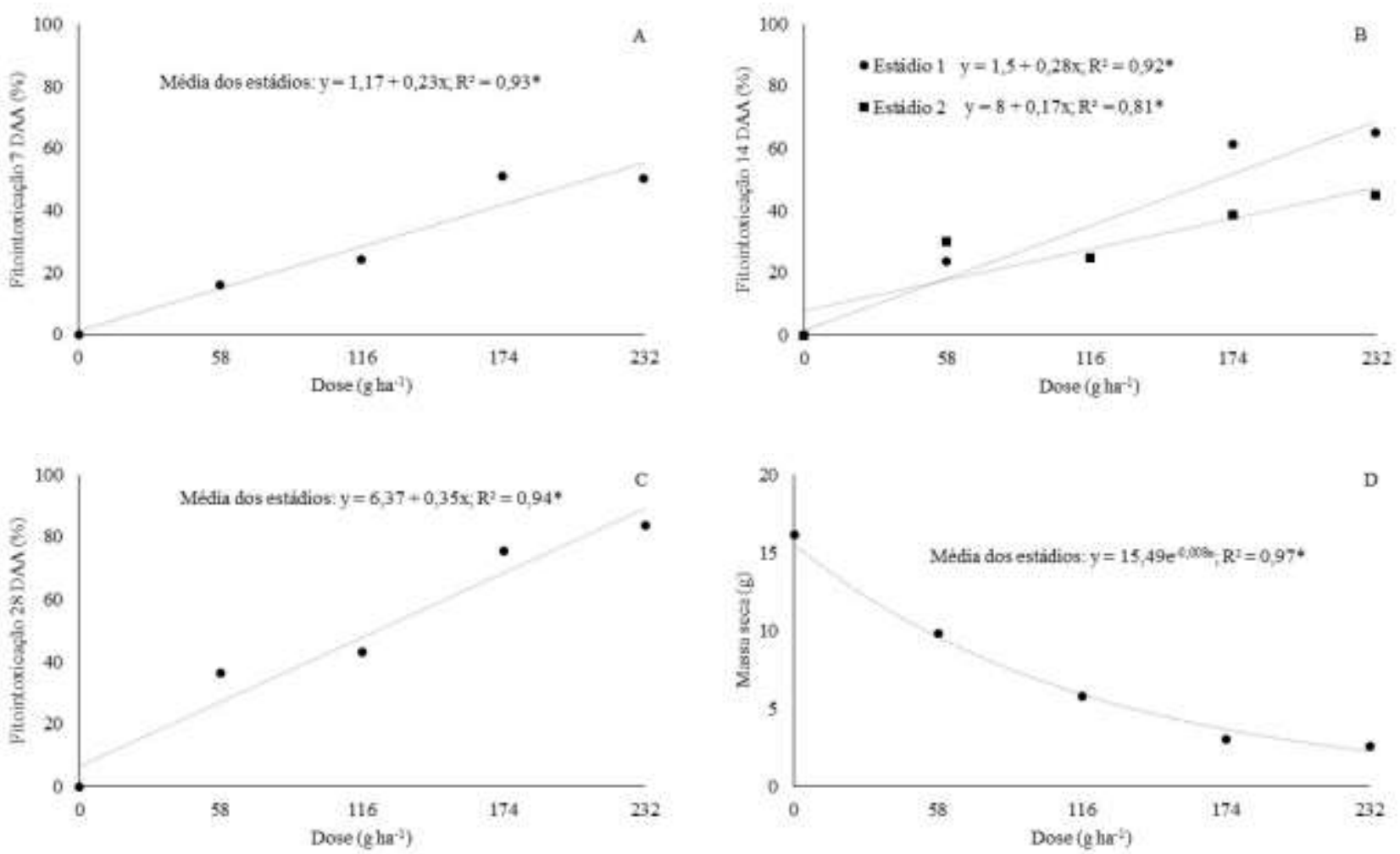

Figura 3 - Fitointoxicação aos 7; 14 e 28 dias após a aplicação (DAA) de glyphosate e massa seca de parte aérea de BRS Tamani. Rio Verde (GO), 2018. Phytointoxification at 7, 14 and 28 days after application (DAA) of glyphosate and shoot dry mass of BRS Tamani. Rio Verde (GO), 2018.

Na avaliação realizada aos 28 DAA, fica evidente a impossibilidade de utilização de doses de glyphosate superiores a $116 \mathrm{~g} \mathrm{ha}^{-1}$ na supressão de BRS Tamani, independentemente do estádio da planta na ocasião da aplicação, tendo em vista os elevados percentuais de intoxicação que estas proporcionaram
(Figura 3C). Nas doses mais elevadas do herbicida, foi possível constatar sintomas de amarelecimento e necrose foliar, além da morte de perfilhos. Para o consórcio de $P$. maximum cv. aruana com soja, foi visualizado que doses equivalentes a $120 \mathrm{~g} \mathrm{ha}^{-1}$ de glyphosate foram capazes de causar restrições no desenvol- 
vimento desta espécie (Concenco et al., 2014). Apesar disto, para evitar que reduções na produtividade de soja fossem visualizadas, os autores do trabalho supracitado concluíram que seria necessário utilizar doses de glyphosate próximas a $480 \mathrm{~g} \mathrm{ha}^{-1}$. Possivelmente, para milho, não seria necessária a utilização de doses tão elevadas, pois esta espécie apresenta potencial competitivo superior ao da soja, e o sombreamento imposto pela cultura auxiliaria na supressão da espécie consorciada.

Com relação à massa seca de BRS Tamani, observa-se que os valores desta variável decresceram linearmente à medida que se aumentaram as doses de glyphosate (Figura 3D). Este resultado corrobora o encontrado para fitointoxicação e indica que quanto maior os danos causados às plantas, menor será a produção de fotoassimilados e, consequentemente, haverá diminuições no acúmulo de massa de parte aérea. Do ponto de vista de supressão, este é um resultado positivo, pois haverá diminuição da competição entre cultura e espécie consorciada. Apesar disto, é importante que esta redução não afete o potencial de produção de palhada após a colheita do milho em segunda safra.

Neste sentido, pode-se concluir que as doses de 58 e $116 \mathrm{~g} \mathrm{ha}^{-1}$ causaram menor dano ao desenvolvimento da forrageira BRS Tamani; entretanto, nota-se que a partir de $116 \mathrm{~g} \mathrm{ha}^{-1}$ há considerável redução no acúmulo de massa. A partir destes resultados, verifica-se que a utilização do glyphosate pode ser alternativa viável para utilização no sistema de consórcio. Além disso, sua utilização pode proporcionar redução de custo com os herbicidas e gerar menor impacto à cultura quando comparado a herbicidas seletivos.

\section{Conclusões}

O aumento de doses de glyphosate proporciona acréscimos nos níveis de intoxicação e redução na massa seca de parte aérea de capimruziziensis e BRS Tamani. O capim-ruziziensis apresenta alta sensibilidade ao glyphosate em função do estádio de aplicação, enquanto para BRS Tamani este comportamento não foi tão evidente.

O glyphosate, em doses próximas de $58 \mathrm{~g} \mathrm{ha}^{-1}$, apresenta potencial para utilização na supressão de capim-ruziziensis, desde que as aplicações sejam realizadas sob plantas com 5 a 7 perfilhos. Para BRS Tamani, doses de glyphosate variando entre 58 e $116 \mathrm{~g} \mathrm{ha}^{-1}$, independentemente do estádio de aplicação, apresentam potencial para serem utilizadas na supressão desta espécie em consórcio com milho.

\section{Referências}

Balbinot Junior AA, Moraes A, Veiga A, Pelissarill A, Dieckow J (2009) Integração lavoura-pecuária: intensificação de uso de áreas agrícolas. Ciência Rural 39(6):1925-1933.
Brighenti AM, Souza Sobrinho F, Rocha WSD, Martins CE, Demartini D, Costa TR (2011) Suscetibilidade diferencial de espécies de braquiária ao herbicida glifosato. Pesquisa Agropecuária Brasileira 46(10):12411246.

Concenco G, Machado LAZ, Galon L, Correia IVT, Santos SA, Palharini WG (2014) Supressão química do crescimento de Panicum maximum cv. aruana cultivado em consórcio com a cultura da soja. Agrarian 7(24):176-188.

Ceccon G (2013) Consórcio milho-braquiária. Embrapa Agropecuária Oeste - Livro técnico (INFOTECA-E).

Ceccon $G$, Matoso $A O$, Neto Neto $A L$, Palombo $L$ (2010) Uso de herbicidas no consórcio de milho safrinha com Brachiaria ruziziensis. Planta Daninha 28(2):359-364.

Chioderoli CA, Mello LMM, Holanda HV, Furlani CEA, Grigolli PJ, Silva JOR, Cesarin AL (2012) Consórcio de Urochloas com milho em sistema plantio direto. Ciência Rural 42(10):1804-1810.

Costa NV, Lima PEJ, Ritter L, Silva PV, Fey E (2013) Avaliação do glyphosate e paraquat no manejo da Brachiaria ruziziensis. Revista Brasileira de Herbicidas $12(1): 31-38$.

Dan HA, Barroso ALL, Dan LGM, Procópio SO, Oliveira J, Constantin J, Feldkircher C (2011) Supressão imposta pelo mesotrione a Brachiaria brizantha em sistema de integração lavoura-pecuária. Planta Daninha 29(4):861-867.

Dan HA (2013) Fertilizantes como veículo de semeadura e seletividade de herbicidas no estabelecimento de milho em consórcio com braquiárias. UEM (Tese de Doutorado em Agronomia).

Ikeda FS, Victoria FR, Marchi G, Dias CTS, Pelissari A (2013) Interferências no consórcio de milho com Urochloa spp. Ciência Rural 43(10):1763-1770.

Jakelaitis A, Daniel TAD, Alexandrino E, Simões LP, Souza KV, Ludtke J (2010) Cultivares de milho e de gramíneas forrageiras sob monocultivo e consorciação. Pesquisa Agropecuária Tropical 40(4):380-387.

Jakelaitis A, Ferreira SA, Lopes PJ, Silva AA, Ferreira LR, Vivian R (2006) Efeitos de densidade e época de emergência de Brachiaria brizantha em competição com plantas de milho. Acta Scientiarum. Agronomy 28(3):373-378.

Jakelaitis $A$, Silva $A A$, Ferreira LR, Silva AF, Pereira JL, Viana RG (2005) Efeitos de herbicidas no consórcio de milho com Brachiaria brizantha. Planta Daninha 23(1):69-78. 
Lima SF, Pereira LS, Sousa GD, Vasconcelo, SA, Jakelaitis A, Oliveira JFA (2018) Influence of glyphosate underdoses on the suppression of Panicum maximum cultivars. Arquivos do Instituto Biológico 85:(1-8) e0812017.

Merotto Júnior A, Wagner J, Meneguzzi, C (2015) Effects of Glyphosate and foliar application of micronutrients in transgenic soybean. Bioscience Journal 31(2):499-508.

Monquero PA, Cury JC, Chistoffoleti PJ (2005) Controle pelo glyphosate e caracterização geral da superfície foliar de Commelina benghalensis, Ipomoea hederifolia, Richardia brasiliensis e Galinsoga parviflora. Planta Daninha 23(1):123-132.

Petter FA, Pereira PL, Procópio SO, Cargnelutti A, Volf MR (2011) Seletividade de herbicidas à cultura do milho e ao capim-braquiária cultivadas no sistema de integração lavoura-pecuária. Semina: Ciências Agrárias 32(3):855-864.

Pariz CM, Andreotti M, Tarsitano MAA, Bergamaschine AF, Buzetti S, Chioderoli CA (2009) Desempenhos técnicos e econômicos da consorciação de milho com forrageiras dos gêneros Panicum e Brachiaria em sistema de integração lavoura-pecuária. Pesquisa Agropecuária Tropical 39(4):360-370.

Pariz CM, Andreotti M, Azenha MV, Bergamaschine AF, Mello LMM, LIMA RC (2011) Produtividade de grãos de milho e massa seca de braquiárias em consórcio no sistema de integração lavoura-pecuária. Ciência Rural 41(5):875-882.

Rodrigues GS, Medeiros RD, Albuquerque JAA, Smiderle OJ, Alves JMA, Silva AA (2018) Manejo químico de Urochloa ruziziensis consorciado com soja na savana de Roraima. Revista Brasileira de Herbicidas 17(2):581-1.
Santos HG, Jacomine PKT, Anjos LHC, Oliveira VA, Lumbreras JF, Coelho MR, Almeida JA, Cunha T JF, Oliveira JB (2013) Sistema brasileiro de classificação de solos, terceira ed. Embrapa Solos, Rio de Janeiro.

Seidel EP, Gerhardt S, Fernando I, Castagnara DD, Neres MA (2014) Efeito da época e sistema de semeadura da Brachiaria brizantha em consórcio com o milho, sobre os componentes de produção e propriedades físicas do solo. Semina Ciências Agrárias 35(1):55-66

Silva PIB, Fontes DR, Moraes HMF, Gonçalves VA, Silva DV, Ferreira LR, Felipe RS (2014) Crescimento e rendimento do milho e da braquiária em sistema consorciado com diferentes manejos de plantas daninhas. Planta Daninha 32(2)301-309.

Silva DV, Freitas M, Souza MF, Queiroz GP, Melo CAD, Silva AA, Reis MR (2016) Glyphosate herbicide use in Urochloa brizantha management in intercropping with herbicide-resistant maize. Planta Daninha 34(1):133-141.

SOCIEDADE BRASILEIRA DA CIÊNCIA DAS PLANTAS DANINHAS - SBCPD (1995) Procedimentos para instalação, avaliação e análise de experimentos com herbicidas.

Spader V, Vidal RA (2001) Seletividade e dose de injúria econômica de nicosulfuron aplicado em diferentes estádios de desenvolvimento da cultura do miIho. Ciência Rural 31(6):929-934. 